\title{
Article
}

CHI. \& WTO REV. 2017:1; 35-60

http://dx.doi.org/10.14330/cwr.2017.3.1.02

pISSN 2383-8221 • elSSN 2384-4388

China and WTO Review

\section{Can Nordic Extended Collective Licence Be Transplanted to China?}

Haijun $\mathrm{Lu}^{*}$

Collective Management Organizations' lack of good governance and transparency is incompatible with the Extended Collective License (ECL). The ECL might be unfit for the digital world. National treatment for foreign rightsholders is not guaranteed. The ECL arrangement cannot pass the three-step test. The ECL in the draft of the third amendment of the Chinese Copyright Act may result in an unbalanced competition between Chinese copyright holders and foreign copyright holders. In the online world, the implementation of an ECL may be risk violating international copyright conventions. In light of not only China's poorly established CMC but also Chinese CMOs' lack of good governance, ECLs either should be put on hold (at least for now) or should only be exercised in special cases in which international copyright conventions permit the use of a non-voluntary licence. With regard to the possible abuse of ECLs, this article proposes the establishment of either mandatory international regulations or soft-law guidance.

Keywords: extended collective licence, CMOs, good governance

\section{INTRODUCTION}

The draft of the third amendment to the Chinese Copyright Act ${ }^{1}$ creates an "extended collective licence" ("ECL"), which originated from the Nordic copyright acts (1960-61). The ECL originally dealt with broadcasting, gradually

* Associate Professor of Law at the University of International Business and Economics ("UIBE"), Beijing. LL.M./Ph.D. (Zhongnan Univ. of Economics \& Law). ORCID: http://orcid.org/000o0002-3584-4276. This research paper was supported by UIBE Networking and Collaboration Center for China's Multinational Business. The author may be contacted at: shangbaking@126. com / Address: UIBE Law School, No. 10, Huixindong Street, Chaoyang District, Beijing 100029 P.R. China. 
extending to other core areas, including photocopying by educational institutions, business enterprises and libraries, for use by the visually impaired, and the national public television companies and cable companies (for retransmission). ${ }^{3}$ The ECL has been described as a subtle mixture of autonomy and state intervention with an effective advantage in the field of mass licensing, more than individual or traditional collective licensing. ${ }^{4}$ Although the ECL has been labelled as a "modality of rights administration or management," this label makes no sense in determining whether the ECL is a rule that limits copyright.

When determining the legal essence of an ECL, its practical effects should be considered as the decisive element. ${ }^{6}$ ECLs' distinct designs have imposed varying degrees of limitations on copyrights. In contrast with other copyright limitations e.g., compulsory licences, the test is whether an ECL as a limitation to copyright is subject to the efficiency, transparency, and accountability of the collective management organizations ("CMOs"). In other words, the legal essence of an ECL must be contextually judged. [Emphasis added]. Therefore, it is uncertain whether an ECL per se represents a limitation, if the CMOs' actual operating states are not taken into account. Only an ECL in a well-established collective management of copyright system ("CMC") will be easily exempt from limitations on copyright. Nevertheless, existing ECL laws suggest that even in a well-established CMC, ECLs seem to be closer to a system of copyright limitation ${ }^{7}$ that either fully or partially prevents the possibility that non-members can exercise copyrights on an individual basis. ${ }^{8}$ The ECL provides a solution for outsiders such as nonmembers, foreigners and unknown parents of orphan works ${ }^{9}$ so that it is regarded as the appropriate method of ensuring successful copyright management in the digital age. ${ }^{10}$ The ECL has thus greatly facilitated both access and distribution. Increasingly fragmented ${ }^{11}$ copyrights have frustrated users seeking multi-source or legitimate authorizations. This reduces the value of copyright because some users simply abandon the search for authorization. ${ }^{12}$ With an ECL, users do not have to seek out very rightsholder for permission. Theoretically, all rightsholders can be compensated and consequently the interests of almost all of the stakeholders are realized. With respect to public interest, the ECL could be a quick way to establish tariffs for the use of materials that educators wish to access. ${ }^{13}$ An ECL might be a method that is conducive to copyright realization and clearance in the digital age. The ECLs may thus accelerate the acquisition of rights ${ }^{14}$ with the effect of 
increasing both the efficiency and promptness of royalty collection. ${ }^{15}$ Moreover, public interest seems to be fulfilled by the ECLs.

Despite all of its possibly exaggerated advantages, the author is of the opinion that an ill-designed ECL is especially unsuited in the Chinese context due to Chinese CMOs' lack of good governance and transparency. It is claimed by Chinese lawmakers that ECLs are created to facilitate the use of works. ${ }^{16}$ However, it seems that the ECL described in the third amendment to the Chinese Copyright Act is neither a system of copyright limitations, ${ }^{17}$ nor in public interest. Therefore, even though an ECL is included in some legislations of, e.g., the Nordic countries with reportedly beneficial effects, the ECL in the third amendment to the Chinese Copyright Act, especially the all-encompassing ECL in the first draft, seems inauthentic and may only expand the abuse of public power. It is harming the economic and moral rights of rights holders and hampering normal copyright transactions, as well.

The author has no intention of overthrowing the ECL arrangement in its entirety. Instead, he is willing to provide elaborations on possible drawbacks to be wary that an ill-designed ECL may mercilessly devour all of its claimed benefits. In general, an ECL can only be operated smoothly in an extremely limited manner. With the expansion of the scope of the ECL's application, the negative effects discussed below will be amplified. In terms of China's current CMC situation, it is advisable to postpone the ECL plan until CMC is well established.

Further, the author calls for the establishment of the necessary special compulsory international regulations on ECL or alternatively, some softlaw guidance, ${ }^{18}$ because various forms of ECLs have been inserted into some jurisdictions with both good effects (e.g., Nordic countries) and bad effects (e.g., Russia). This paper is composed of five parts including a short Introduction and Conclusion. Part two will discuss the balance of interests of rights holders and users in the context of ECLs. Part three will evaluate the ECL in the digital age. Part four will examine the international context. 


\section{The Delicate Balance of Interests of RightShOLders AND USERS IN THE CONTEXT OF ECLs $^{19}$}

\section{A. Authors' Side}

\section{Burden borne by Authors}

The ECLs may place extra burden ${ }^{20}$ on authors - particularly foreign authors. Although the ECLs generally permit rights holders to opt out of the system, it is difficult to enforce the right in practice because of asymmetric information, especially in the case of foreign rights holders. [Emphasis added] It is important to recognize that works of rights holders have been used, and identify which CMOs authorize the use of their works if there are multiple CMOs in each category. ${ }^{21}$ Even though publicity rules are recommended, in which the names of nonmembers should be published on the internet or another platform, ${ }^{22}$ a portion of the transaction cost actually shifts to the rights holders. ${ }^{23}$ A burdensome optout system might be transformed into a de facto formality. ${ }^{24}$ The 'no formalities' principle guarantees the exclusivity of copyrights. Regardless of the prohibition of opting out, formality under Article 5(2) of the Berne Convention hinges on whether the exclusivity of the copyright remains intact. In principle, if the ECL is confined to areas in which $\mathrm{CMC}$ is a justified, normal method of exercising a right - the risk of violating the "no formalities" principle - is relatively lower, because, regardless of whether rights holders are opting out, they would exercise the right in the same way. If the ECL is not confined as such, the risk will be higher because rights holders must opt out (i.e., a de facto formality) to exercise their rights individually. Thus, the ECL might be safely exercised only in special cases in which a non-voluntary licence can be used. ${ }^{25}$

\section{Contrary to Authors' Interests}

An ECL may be contrary to author's interests. First, in principle, CMOs' privilege should only cover rights that are legally impossible or impractical to exercise individually. Some rights holders will resist attempts to embrace CMC by parties such as publishers and film companies through contractual arrangements which have partially resolved the copyright fragmentation paradox. In light of this socalled paradox, e-distributors have played an increasingly important role. Because 
the paradox has been addressed at least to a certain degree, especially with the aforementioned digital technology, it is unreasonable for CMOs to intervene in areas that are individually controllable by rights holders. An ill-designed ECL might ignore these emerging changes, especially in the digital environment and cover the forbidden area. [Emphasis added]. Second, CMOs should generally treat non-members as the same members under an ECL regime. It sounds good, but might be unfair to non-members. On the one hand, copyrights include both property rights and moral rights with multiple powers. Copyright is more than just a mere right to be paid. ${ }^{26}$ If unauthorized by rights holders, CMOs may infringe not only property rights, but also morality. Authors' exclusive rights will degenerate into a simplistic remuneration right in an ECL, ${ }^{27}$ if it fails to cover other aspects of authors' interests such as moral rights. On the other hand, rights holders are entitled to dispose of their rights because copyright is a type of private right. Some rights holders may command greater royalties through their own private negotiations, whereas others prefer different types of arrangements. It is thus unfair to non-members if similar contract terms are applicable to them without notice or authorization.

\section{B. The Benefit to Users}

The ECLs may not benefit users. Although they are said to benefit users by facilitating the acquisition of an adequate repertoire, ${ }^{28}$ it may be unnecessarily burdensome to users. More specifically, ECLs are distinguished from nonvoluntary licences because they are usually labelled as a so-called opt-out arrangement for the rights holders. ${ }^{29}$ In a voluntary ECL, rights holders are entitled to withdraw from the ECL arrangement, which then would not cover them. In this case, however, users have no feasible method of recognizing whether a rights holder has opted out. One solution is the so-called 'publicity system' in which the names of excluded rights holders are listed on a platform. ${ }^{30}$

Unfortunately, it is very difficult to set up and enforce a publicity system mainly because it would require users to continuously monitor the list. Here, rights holders may withdraw from an ECL at any time, even though some ECLs require the opt-out to be performed during a specific period. It would be unnecessarily burdensome to require users, especially non-commercial users, to monitor such a list frequently. In this regard, the publicity system would pose more problems 
than it solves. This uncertainty created by a publicity system would scare off potential users for the risk of liability for copyright infringement. Consequently, the declared efficacy of an ECL should be greatly discounted.

\section{The Feasibility of ECLs}

It should be noted that an ECL is feasible only in special settings. If there is more than one $\mathrm{CMO}$ in a particular category and no CMO has market exclusivity, it is difficult, if not impossible, to implement an ECL without feasible criteria to determine which CMO is broadly (or sufficiently) representative. In addition, the ECL is on a premise that there are clear boundaries between works. However, no consistent standards exist about how to classify works. In other words, it is difficult to categorize different types of works. Although only one CMO is obliged to manage each type of work under law, it is possible for a single work to be managed by multiple CMOs. In this circumstance, it may be difficult to determine that a particular $\mathrm{CMO}$ has the right to manage a work. Determining which $\mathrm{CMO}$ has the right to manage a work in the context of an ECL may be even more difficult. In addition, under an ECL arrangement, CMOs (especially immature ones) may attempt to assume a greater responsibility than it can manage. When a large number of distinct rights holders exist, managing the rights for the many types of exploitation is thus extremely complicated. ${ }^{31}$

The rights holders of certain works are dynamic rather than static due to a possible transfer or reversion of copyright. ${ }^{32}$ Different rights holders may have different attitudes about an ECL arrangement. Therefore, within an ECL, especially a voluntary ECL, it is necessary for a CMO to track all of the changes related to certain works. In both obligatory and voluntary ECL, it is necessary for the $\mathrm{CMO}$ to issue the licence in order to locate non-members entitled to remuneration. In a voluntary ECL, moreover, it should be determined whether a rights holder hopes to opt out of the ECL arrangement. If changing the identities of the rights holders of certain works, the difficulty of ascertaining those rights holders is increasing. What if the transferee wants to opt out, e.g., when the transferor accepts the ECL arrangement?

In such a situation, it is necessary for the transferee to opt out on a designated platform. In theory, therefore, the CMO is required to continuously monitor the platform so that it does not cover the works of rights holders who have opted 
out. However, this is obviously a complex task for a $\mathrm{CMO}^{33}$ with an excessive administrative cost, especially in a jurisdiction such as China in which there may be a large number of outsiders. In general, in the author's view, with an increased number of outsiders, the justification for an ECL will gradually decrease. The ECL will collapse once the number of outsiders reaches a certain level.

\section{ECLs Are Not a Panacea in the Face of Digital Challenges}

\section{A. P2P File Sharing}

In response to the challenge posed by P2P file sharing, two types of proposals a control-based regime and a payment-based regime - have emerged as possible solutions. On the one hand, under a control-based regime, P2P file sharing is unlawful without the authorization of the rights holders. For stronger control over digital works, technical measures have been developed. In addition, some P2P operators (e.g., Napster) have disappeared from lawsuits. ${ }^{34}$

On the other hand, a payment-based regime has been developed to legalize file sharing under a compulsory licence or similar alternatives such as an ECL. This type of regime can be defined as the "compensation without control." 35 Among all of the proposals, the most fundamentals are those of a levy-based compulsory licence, a mandatory CMC and an ECL. The other types of proposals are more or less based on the main structure of the three above-mentioned proposals. Under a levy-based compulsory licence (perhaps with an opt-out mechanism), which limits copyright, file sharing is lawful and a levy on certain products or services is charged to compensate authors. In a mandatory CMC scheme, rights can only be exercised collectively. Mandatory CMC limits copyright because it inevitably addresses the full-fledged exclusivity of copyright (e.g., moral rights are limited if rights holders are legally obliged to collectively manage their rights).

The ECL has much in common with the levy-based compulsory licence, although proposals are generally accompanied by a so-called opt-out system. In an ECL, similar to a levy-based compulsory licence, copyrights are managed on a collective basis (i.e., levies or royalties are collected by CMOs on the basis of homogenizing all types of works). However, "collective management is not 
a one-size-fits-all model for rights management. ${ }^{36}$ Digital distribution markets require innovative and flexible licences. ${ }^{37}$ The ECL, even with a so-called opt-out arrangement for rights holders, may still touch upon the core business interests of some rights holders and potentially encourage online piracy, especially when the ECL arrangement is abused. In sum, the compulsory licence, the mandatory $\mathrm{CMC}$, and the ECL can be defined as "trading control for compensation." These proposals might not adhere to international copyright conventions in their deprivation to varying degrees of the exclusivity of rights holders' copyrights.

The advantages of a "compensation without control" mechanism, including an ECL, are often defined as being conducive to public interest by improving access to works, while providing revenue for rights holders with lower transaction and enforcement costs. ${ }^{39}$ Notwithstanding, such mechanisms have the following disadvantages.

First, a "compensation without control" mechanism might violate the nature of copyright as a private right. CMOs have proved to be slow to follow up with the quickly evolving digital environment, ${ }^{40}$ because $\mathrm{CMC}$ does not reflect individual rights holders' intent. ${ }^{41}$ In contrast, direct licensing or licensing by their agents provides opportunities for new business models. ${ }^{42}$ Under a levy-based compulsory licence or an ECL, users do not have to seek out rights holders to obtain permission regardless of its convenience to do so. Such schemes tend to ignore the characteristics of different types of works. It is not alarmist nonsense to state that an ECL could have devastating consequences for rights holders in the online world which stands in stark contrast to the offline world. It is thus unwise to simply transplant a possibly workable system in the traditional offline world to the digital online world without rigorous consultation and impact assessment. If a user can work in whatever manner they want, including uploading to a P2P website (provided that they haves paid a similar flat annual fee to the relevant CMOs), theoretically, user-enabled access will be available worldwide. If the public can access the works for free, why incur the expense and inconvenience of purchasing a copy? This would be a disaster for rights holders. ${ }^{43}$

Second, the "compensation without control" mechanism might not be feasible. The retention of control over works might be newer-business-models friendly than the "compensation without control" mechanism. As good licensing processes should be friendly to new business models, it should both reward and 
encourage business investment and innovation. ${ }^{44}$ Unlike the compulsory licence, the mandatory $\mathrm{CMC}$ or the ECL, ${ }^{45}$ with control on works, ${ }^{46}$ both successful and emerging business models (such as Copyright Bank and COPYMART) ${ }^{47}$ will not only be safely developed, but also provide increased opportunities for creative upstarts. ${ }^{48} \mathrm{~A}$ uniform mechanism might distort emerging markets that provide for price differentiation and thus an efficient property regime. ${ }^{49}$ Even if the "compensation without control" mechanism is implemented, all the concerned works would not be freely shared by consumers because the creative industry is unwilling to abandon control over their works to enjoy commercial potential continuously.

Third, "compensation without control" mechanisms, such as the noncommercial use levy ("NUL"), a levy-based compulsory licence, ${ }^{50}$ might be expensive. The fatal drawback of "compensation without control" mechanisms lies in not only the difficulty of fairly determining compensation, but also high administrative costs. ${ }^{51}$ To address this issue, some proposals, such as NUL, attempt to promote the accuracy of the levies on providers of certain products and services that are value-enhanced by file sharing. ${ }^{52}$ The value of NUL is negotiated among the stakeholders ${ }^{53}$ with a varying amount on any given item. It is based on the extent to which file sharing enhances that item's value. ${ }^{54}$ The reasonability of NUL will depend on whether the levy is more expensive to providers than implementing digital right management ("DRM") technology and policing users on behalf of rightsholders. ${ }^{55}$ Even NUL cannot be implemented due to non-clear criteria, it will be a very costly method for fairly compensating rightsholders.

\section{B. Orphan Works}

To delicately strike the balance between copyright protection and access to works in the digital era, both demand for use and the issue of orphan works must be put on the agenda. Mass use may be in either the public (such as library or archival mass digitalization for preservation), or private interest (such as for-profit netcasts). One can argue that ECL could support a system for mass authorizations. ${ }^{56}$ An adequate repertoire is usually described as "a necessity of mass use. ${ }^{, 57}$ For commercial use, regardless of the overestimated demand for an adequate repertoire in the digital age, certain adequate repertoire demands can be also met by voluntary $\mathrm{CMC}$, with CMOs playing beneficial roles in online 
licensing. If enough rights holders join CMOs thanks to robust $\mathrm{CMC}$ systems, CMO repertoires will be relatively adequate for users while placing no limitations on rights holders' freedom to exercise their rights in other ways. For public interest, however, the context of library or archival mass digitalization should be considered for preservation. In this course, the orphan works issue must be effectively addressed.

Notwithstanding that voluntary ECLs are described as benefitting orphan works, especially in the digital era, it is not the only viable solution. In theory, some scholars argue that compulsory licensing may do the same work well. ${ }^{58}$ E.g., Canada has implemented a public-authority, licence-based approach. Following the Canadian approach, if a user has conducted a 'diligent search' to find the rights holder but has been unsuccessful, a public authority can issue a non-exclusive and time-limited licence to use the orphan work (provided the user has applied for such a licence). ${ }^{59}$

For orphan works, a "limitation-on-remedy model" might be a better choice than other approaches explored above. Only when the rights holder cannot be identified (or who can be identified but not located) following a good-faith, reasonably diligent search shall be entered in the orphan works list. Prior to commencing use, if the user has performed a reasonably diligent search with goodfaith to locate the rightsholder of the work in question but has been unsuccessful, the user will be privileged to use the work under the authorization of the law. For commercial use, the user should be required to register necessary information about the orphan work such as the name of the rights holder - readily available records of the diligent search and information about the use of the orphan works in the National Copyright Administration of China ("NCAC") - to establish a publicly accessible database. ${ }^{60}$

With respect to the "reasonable diligent search" ${ }^{\text {"61 }}$ requirement, whether a search meets the requirements of reasonableness and diligence will vary greatly according to the category of the work. ${ }^{62} \mathrm{~A}$ formal standard ${ }^{63}$ must be thus defined for more certainty. ${ }^{64} \mathrm{~A}$ reasonable search includes items such as: records of competent authority, Internet search engines, on-line telephone directories and address directories, print telephone directories when the owner's geographical location is known, databases of trade associations or professional groups, CMOs' databases, and ownership information appearing on the face of the orphan works. ${ }^{65}$ 
Once the rights holder surfaces or is located, the legal authorization to use the work becomes invalid. This effect is retroactive. However, to protect the user's reliance interest, remedies should be limited as follows. On the one hand, for non-commercial use, no award of monetary relief should be made, if the user expeditiously ceases the use of the works concerned after receiving notice of the claim for infringement. In other words, non-commercial users need not to pay for their past use.

However, they should pay for future or on-going use if there is an agreement between the rights holder and the user for permission and payment. If the user has prepared and exploited derivative works with a significant amount of the user's expression but based on the underlying works of rights holders, any injunctive or equitable relief granted by the court shall not restrain users' continued preparation and use of the derivative work, provided that the user pays reasonable compensation for ongoing use and reasonable attribution, to the author and copyright owner. The above arrangement tends to be a simple consumer-friendly legal framework. On the other hand, take a look at commercial exploitation including mass digitization schemes such as Google's Digital Library Project (non-orphan works). If the rights holders resurface or are located in this case, no award for monetary damages will be ordered other than the payment of reasonable compensation for the past use. Naturally, users must pay for future use unless such use is royalty-free. If the user has prepared and exploited derivative works with a significant amount of the user's expression but based on the rights holders' works, any injunctive or equitable relief granted by the court will not restrain the user's continued preparation and use of the derivative work, provided the user pays reasonable compensation for such preparation and ongoing use and provides reasonable attribution to both the author and the copyright owner. ${ }^{66}$

With respect to orphan works, the "limitation-on-remedy model" seems to provide a carefully crafted limitation of remedies with adequate flexibility, partly following the approach to orphan works that has been followed by the US Copyright Office since 2006. ${ }^{67}$ Nevertheless, the "limitation-on-remedy model" represents innovation and possible progress compared to the US Copyright Office's approach. The US Copyright Office's 2006 Report on orphan works show that even if a good faith and reasonably diligent search has been performed, the use remains categorized as copyright infringement. ${ }^{68}$ This looks like a paradox: 
if use is copyright infringement, why can it continue? In the "limitation-on-remedy model," if a good faith and reasonably diligent search has been performed, the use of the orphan works concerned evolves into an authorized use (authorized by law, but without authorization by the rights holder). Once the holder surfaces or is located, the legal authorization to use the work becomes invalid, although there are some transitional arrangements in place for 'relying parties' (i.e., existing users). It seems that the "limitation-on-remedy model" is more viable than the approach taken by the US Copyright Office.

Let us now turn to the ECL. The exceptions and limitations on copyright generally concern particular uses rather than particular categories of copyrighted works. ${ }^{69}$ It is the same case with the ECL. ${ }^{70}$ Orphan works, however, might relate to all categories of use. In this regard, the general approaches to copyright exceptions/limitations and the ECL may be unsuitable for addressing orphan works issue. On the one hand, if orphan works issues arise in the context of a particular use of work, such as library or archival mass digitalization for preservation, the ECL could play an enabler role. On the other hand, in a general sense, the ECL loses this role. Article 50 of the Danish ECL provides that one of the preconditions for an ECL is to conclude an agreement between users and the CMOs concerned, regarding the exploitation of the work that is the subject of the ECL. The provisions of the agreement will cover non-members. In practice, however, not only commercial users, but also ordinary consumers will encounter orphan works. It is difficult to imagine an agreement on the use of such works in every field, particularly regarding non-commercial use. If there is no agreement, no ECL can be used to cover orphan works because its preconditions have not been met. Accordingly, the user is not entitled to use the orphan works. For this reason, concerns related to orphan works are not addressed.

In contrast to the ECL, the "limitation-on-remedy model" has the following advantages. First, there are distinct arrangements for both non-commercial and commercial uses. Regarding the remedies limitation, e.g., non-commercial users do not have to pay for the past use, while commercial users should pay reasonable compensation for the past use. Second, in this model, the exclusivity of copyright remains intact. Rights holders can exercise their rights as they desire without a compulsory (or similar) licence arrangement based on a perhaps-abused ECL. Users are not entitled to freely use works regardless of the circumstances. 
Although use of the works at issue may be authorized as orphan works, they are subject to a "reasonable diligent search." If the rights holders resurface, they can exercise their rights and call upon users to cease using the works.

Third, possible benefits of easy access are respected in the limitation-onremedy model under a regime in which the users can use the works of unsurfaced rights holders until those rights holders resurface. Indeed, such rights holders rarely resurface. ${ }^{71}$ Even if rights holders do resurface, uses may continue with rights holders' authorization plus an agreed reasonable licence fee. While fulfilling its public-interest mission, however, the law can specify that such uses may be made on a royalty-free basis. It is worth noting that if library or archival extends beyond a public-interest mission, it is necessary to pay a reasonable and equitable fee to the relevant rights holders. Also, it is understood that rights holders are entitled to decide whether to authorize continuing use. ${ }^{72}$

Fourth, in the "limitation-on-remedy model," users will not pay unnecessary royalties. Especially, in the ECL, users shall pay for all non-members even if some do not want to be paid. In contrast, the "limitation-on remedy model" requires users to pay only for those resurfaced rights holders who claim royalties. It is also important to keep in mind that the ECL might selectively ignore the existence of fair-use exceptions and that 'fair use' might degenerate into 'fared use. ${ }^{73}$

The "limitation-on-remedy model," however, mirrors reality to a greater extent than ECL. Fifth, in the "limitation-on-remedy model," resurfaced rights holders can obtain a reasonable licence fee. In an ECL, however, although the extension effect covers orphan works, it is virtually impossible for CMOs to distribute royalties to rights holders because it is unreasonable to expect that a CMO especially one that is not well established - will conduct a diligent search in goodfaith for the relevant rights holders.

\section{The InTERnational Context}

\section{A. National Treatment}

The ECLs in China may violate principles of international copyright conventions. Compared to domestic rights holders, however, foreign rights holders under an ECL regime are more inclined to be treated unfairly because the drawbacks of 
ECL will be magnified in situations involving foreign rights holder. The following should be noted here: (1) It is more difficult for foreign rights holders to discover whether their works are being used pursuant to an ECL; (2) In various situations, foreign rights holders are not paid for reasonable remunerations; and (3) In general, a certain percentage of royalties collected are withheld to fund projects that are in the national public interest, e.g., to advance cultural or social goals that do not benefit foreign rights holders. ${ }^{74}$ In such situations, national treatment for foreign rights holders is not guaranteed. In theory, a well-run CMO in an ECL should benefit foreign, non-member rights holders. In practice, even in the Nordic countries where ECLs were born, foreign rights holders remain truly unpaid for most ECL schemes.

On the other hand, an ill-run CMC will aggravate the adverse conditions of unfair treatment to foreign rightsholders. As there are no international conventions that prescribe compulsory regulations for ECLs, they may be badly designed. In addition, a well-designed ECL may be created in the context of either well or ill established CMC. In this regard, each type of CMC is displaying distinct attributes. In particular, if a well-designed ECL is created with a well-established $\mathrm{CMC}$, the ECL tends to play an 'enabler' role for the exercise of the rights at issue. Conversely, if a well-designed ECL is created in the context of an ill-established CMC, the ECL tends to play a 'limiting' role with respect to the exclusivity of copyrights. Needless to say, an ill-designed ECL in an ill-established CMC will have ill effects on foreign rights holders.

\section{B. The Three-step Test}

The ECL included in the third amendment of the Chinese Copyright Act is illdesigned in the context of an ill-established CMC. Accordingly, if an ECL is created in China, it will tend to place limitations on copyright which should be subject to the three-step-test laid out in the Berne Convention, the TRIPS Agreement and the WIPO Internet Treaties. Article 9(2) of the Berne Convention provides:

It shall be a matter for legislation in the countries of the Union to permit the reproduction of such works [1] in certain special cases, provided that such reproduction [2] does not conflict with a normal exploitation of the work and [3] 
does not unreasonably prejudice the legitimate interests of the author. ${ }^{76}$

China does not meet all these conditions. The first prong, the application field of ECLs, is very broad in the draft of the third amendment to the Chinese Copyright Act. In other words, the ECL is not applicable in certain special cases. One could argue that the latest draft has further confined the ECL to acting as a selfVideo-On-Demand ("VOD") system, only applicable to special cases. It seems, however, that in justifying a limitation on copyright, denoting a case as 'special' is inadequate. It is crucial that copyright shall be limited only for clear publicpolicy or other rational reasons ${ }^{77}$ such as the public interest ${ }^{78}$ or for the benefit of particular groups of users, ${ }^{79}$ thus preventing hold-up problems. In the case of selfVOD systems, however, there might be neither concern for the public interest, nor hold-up problems.

With respect to the second prong, it is not necessary to discuss the legal status of the members of the CMOs. Instead, we should be concerned about nonmembers who are exposed to the extension effects of ECL arrangements. In the case of non-members, even if the collective exercise of copyright is indeed the only workable mechanism, some want their works freely shared, while others want to distribute their works with "some rights reserved." It is difficult to argue that a mere remuneration regime constitutes a 'normal exploitation' of the works of the group of rights holders. One may consider the total effect of an ECL arrangement as related to the special setting of certain jurisdictions instead of the rules per se when determining whether an ECL arrangement can pass the three-step test. ${ }^{80}$ In the same vein, on the one hand, there is no ECL tradition in China, while, on the other hand, China's ill-established CMOs intrude upon normal business of rights holders. In addition, in the digital era, new business models have partly replaced the role of CMOs, which is also challenged by the ECLs especially in China. In this case, they conflict with the normal exploitation of works. In case of self-VOD systems that take certain technical measures, the use of works is controllable. Accordingly, if someone argues that rights can only be exercised on a collective basis, it should be a scepticism. Also, it is difficult to argue in the case of selfVOD systems, that the ECL does not touch upon the 'normal exploitation' of copyrights. In China, the ECL could not pass the second prong of the test; it will damage the legitimate interests of non-members especially involving nascent 
CMOs regarding the third prong. This is unreasonably in prejudice to the author's legitimate interests in the end. In sum, the ECL's conformity to international copyright conventions cannot be guaranteed.

\section{Super-national Treatment}

The ECL in the draft of the third amendment of the Chinese Copyright Act may result in an unbalanced competition between Chinese and foreign copyright holders. Under the ECL regime, some Chinese scholars argue that if a CMO has concluded enough reciprocal agreements with foreign CMOs, the Chinese $\mathrm{CMO}$ shall meet the requirements to be broadly (or sufficiently) representative of foreign rights holders and can represent even if they are non-members. ${ }^{81}$ This argument is also made by leading scholars in the field of $\mathrm{CMC}^{82}$ In practice, some CMOs in an ECL welcome foreign non-members. ${ }^{83}$ Indeed, most Chinese CMOs have reciprocal agreements with foreign counterparts. The Music Copyright Society of China ("MCSC"), e.g., has signed this type of agreement with more than fifty CMOs. ${ }^{84}$ With the agreement, MCSC, along with its "Confédération Internationale des Sociétés d'Auteurs et Compositeurs" ("CISAC") membership, seems to have theoretically fulfilled the requirement of representation, so that the licences granted by it for certain uses would be extended to foreign non-member rights holders. The draft of the third amendment to the Chinese Copyright Act, however, only extends the scope of collective management to copyright holders in Mainland China. ${ }^{85}$

On the first view, this result is surprising, because the Chinese government's legislative proposals for ECL closely resemble 'rights grabbing' than the promotion of copyright clearance. Put differently, the ECLs in China seem to have been promoted by the Chinese government so that more rights holders would join Chinese CMOs. ${ }^{86}$ In practice, powerful market forces in China have played significant roles similar to those of CMOs, in safeguarding rights holders' copyrights. Some companies and law firms, e.g., have purchased copyrights from rights holders, especially non-members of Chinese CMOs. Then, they often successfully sue copyright users (e.g., Karaoke Cabaret) for copyright infringement. The remedies are described as much higher than the royalties provided under the blanket licence agreement provided by Chinese CMOs. It is possible that without ECL, more rights holders will withdraw from Chinese 
CMOs. Then, the Chinese CMOs may ultimately become extinct. ${ }^{87}$ In practice, although the Chinese copyright system currently does not include an ECL, some Chinese CMOs such as MCSC and the China Audio-Video Copyright Association ("CAVCA") have acted on behalf of the non-members for providing more access. ${ }^{88}$ Consequently, many users have paid for Chinese CMOs, but have been sued for copyright infringement ${ }^{89}$ due to some CMOs' unlawful behaviour. To treat the members of Chinese CMOs and non-members 'equally,' the remedies for copyright infringement have been limited by the third amendment to the Chinese Copyright Law to no more than the royalties charged by the Chinese CMOs under identical circumstances. This limitation has been described as being "intended to suppress copyright-infringement litigation." 90

It is undeniable that some companies and law firms acted like rogue patent trolls. Indeed, some of them have abused the litigation process, causing harm to the healthy creative industry. The ECL and its corresponding provisions such as Section 70(1) in the second draft of the third amendment to the Chinese Copyright Act, however, are strongly suspected of having been designed to confer more power on China's current CMOs. Many Chinese CMOs have been in operation for a long time, but, for various reasons, they only have a small number of members. ${ }^{91}$ Many rights holders hesitate to join Chinese CMOs, worrying about their power, whereas others believe it is unnecessary to join any CMOs. Following the corresponding provisions, even retaining the possibility to excise their copyrights individually, non-member rights holders cannot be paid copyright infringement remedies more than royalties charged by Chinese CMOs under identical circumstances even though those royalties may not represent the real market value of the copyrighted works. ${ }^{92}$ Accordingly, it is almost unnecessary for non-members to enforce their copyrights individually. It should be noted that some of the leading Chinese CMOs have illegally represented all rights holders regardless of their intention to join CMOs. As a result, all Chinese rights holders must be members of monopolistic CMOs that they may disfavour. This would be the Chinese government's real motive for advocating the ECL.

Considering these ulterior motives, it is not necessary for the Chinese government to risk expanding the ECL to cover foreign rights holders, which could violate international copyright conventions. ${ }^{93}$ If China's ECL does not cover foreign rights holders, however, competition between Chinese and foreign rights 
holders would be unbalanced. As mentioned above, the ECLs in ill-established CMCs constitute de facto limitations on copyrights. If the ECL in Chinese copyright law only covers Chinese rights holders, then foreign rights holders would actually receive super-national treatment.

\section{Territorial ECL and the Borderless Internet}

In general, limitations on copyright are applied only in countries in which they have been prescribed. ${ }^{94}$ One could argue that the ECL is not a limitation on copyright. As mentioned above, however, even strictly limited ECLs share characteristics with compulsory licences. Needless to say, an ill-designed ECL limits copyright. In such a situation, an ECL might be safely implemented only in the country in which the ECL has been prescribed. Accordingly, an ECL might be safely implemented in the offline world when the extension effect of the ECLs under national copyright law ${ }^{95}$ does not extend beyond national borders. In the online world, however, the implementation may be violating international copyright conventions because once a work is made available online without territorial restrictions, universal access exists. If the rights holder of the work at issue is a CMO member, there may be less concern because permission to use the work worldwide can be obtained from members. As far as non-members, who have not given permission, are concerned, an ECL might be problematic if its extension effect based on domestic law, extends beyond national borders. ${ }^{96}$ In other words, in the digital world, the implementation of an ECL in one country would mean that users in other countries enjoy the same privileges as those in the country in which the ECL is in place. This might be a foreseeable risk for foreign non-member rights holders. Unfortunately, this risk has come to pass. The infamous allofmp3.ru system in Russia, with 'ECL management' as its basis, claimed that distribution of music was legally allowed by its ECL from all artists and labels. Although allofmp3.ru made no claims about its legality outside of Russia, the music available on that platform was accessible to everyone in the world on the borderless Internet. This obviously dealt a heavy blow to rights holders. Because of forceful interventions by rights holders (primarily phonogram producers), allofmp3.ru was shut down. ${ }^{97}$ If planning to create an ECL for online distribution, it might be advisable to extend it to cover only national rights holders. Actual implementation may pose additional difficulties. 


\section{Conclusion}

As China's CMC is an ill-designed administrative and monopolistic system, it cannot guarantee good governance and transparency of CMOs. ${ }^{98}$ In this regard, many negative consequences ${ }^{99}$ are intensified by either the ECL or its abuse. If the ECL in the third amendment to the Chinese Copyright Act is implemented, an equal consultation mechanism for copyright licensing fees will be more difficult to realize, and rights holders' legal interests will be put at greater risk. Legal interests of non-members as vulnerable groups vis-à-vis CMOs will be damaged because rights holders will be unaware of both the real uses of their works, and the royalties charged by CMOs. It would be worse if supervision is lacking; some CMOs may collude with users to arrange a lower price without notice to rights holders. Under these circumstances, real rights holders' legitimate rights cannot be protected. Consequently, in the course of operating China's copyright system, the ECL is not conducive to realizing the fundamental goal of copyright law, which is the advancement of science and culture.

Generally, an ECL is rooted in a small, homogenous society ${ }^{100}$ with a high degree of trust and transparency. ${ }^{101}$ It used to be built on a traditionally high level of organization ${ }^{102}$ against collective bargaining. ${ }^{103}$ ECLs are the result of the institutionalization of the copyright licensing market. ${ }^{104}$ To transplant an ECL ino a jurisdiction, merely replicating an ECL system is inadequate. ${ }^{105}$ The organizations and culture "that base rights administration on a combination of private agreement and public rules" ${ }^{106}$ should also be incorporated into a national jurisdiction. There is no cultural foundation for the ECL in China. China is not a homogenous society. It neither has a high degree of trust and transparency, nor collective-bargaining tradition. Indeed, the Chinese public prefers individual approaches to solve copyright disputes. ${ }^{107}$

Be cautious of inflammatory ECL schemes that represent a triumph of passion over reason, because some ECLs should be substituted by subjugating passion to reason. Although some scholars single-mindedly throw themselves into a passionate affair with an ECL to provide all types of so-called convenient acquisition of copyrighted works, in the countries that have functioning ECLs, almost all rights holders will be members of CMOs and almost all works of non-members will be orphan works. In other words, the CMC systems of the 
above countries are so mature that their CMOs truly have the ability to act on behalf of rights holders. In China, however, such a basis for an ECL does not exist. China has not yet developed a well-established organizational structure on behalf of rights holders. Indeed, the justification for China's CMOs has been questioned because they do not have the ability to represent authors' true interests. Accordingly, the ECL contained in the third amendment to the Chinese Copyright Act may represent an extension of public power that is unsuitable for China. Eventually, the ECL should now be put on hold or alternatively, exercised only in certain special cases where a non-voluntary licence is used in accordance with international copyright conventions.

\section{REFERENCES}

1. The first Chinese Copyright Act (1990) was revised in 2001 and 2010. The third revision of the Act has been in progress since July 2011. The first draft of the revised provisions of the Chinese Copyright Act was published on the website of the National Copyright Administration of China ("NCAC") on March 31, 2012. On July 6, 2012, the second revised draft of the Chinese Copyright Act was completed. On October 30, 2012, the third draft (unpublished) was completed and delivered to the State Council and the National People's Congress of China ("NPC") Standing Committee. The version for review by the State Council (hereinafter, The latest draft) has been published for consultation since June 6, 2014.

2. In the third amendment to the Chinese Copyright Act, ECLs are set forth in Article 60 of the first draft and the second draft, and Article 63 of the latest draft. Article 60 of the first draft reads:

Authorized by rightsholders and on behalf of the interests of rightsholders across the country, CMOs may apply to the copyright administration department of the State Council to represent all rightsholders in enforcing their copyrights or neighbouring rights unless the rightsholders advocate otherwise in a written description.

In contrast to the ECL in the first draft (it looks like a general ECL), the second draft restricts the scope of the ECL to radio broadcasts, TV stations and karaoke parlours. In the latest draft, the scope of the ECL has been further restricted to karaoke parlours. It seems that the ECLs in the second and the lastest draft are specific.

3. T. Riis \& J. Schovsbo, Extended Collective Licenses and the Nordic Experience: It's a Hybrid but is it a Volvo or a Lemon?, 33 COLUM. J. L. \& ARTS 473-4 (2009-2010).

4. Id. at 472.

5. See Directive 2001/29/EC of the European Parliament and of the Council of 22 May 2001 on 
the harmonisation of Certain Aspects of Copyright and Related Rights in the Information Society. Whereas Clause art.(18). It reads as follows: "This Directive is without prejudice to the arrangements in the Member States concerning the management of rights such as extended collective licences." Four Nordic countries (but not Iceland) write ECLs under the chapter "Management of Rights." See Z. Zhang, Transplantation of an Extended Collective Licensing System - Lessons from Denmark, 47 IIC - Int'L Rev. Intell. Prop. \& Competition L. 666 (2016).

6. Supra note 3, at 485.

7. The ECLs necessarily contain an element of non-voluntary licenses. See WIPO, Collective Administration of Copyright and Neighbouring Rights, Study on, and Advice for the Establishment and Operation Organizations [R]. WIPO Publication No. 688(E), 1990 (hereinafter WIPO study (1990)), 『 264, available at ftp://ftp.wipo.int/pub/library/ebooks/ wipopublications/wipo_pub_688(e).pdf (last visited on Jan. 30, 2017).

8. A. Strowel, The European “ECL” Model, 34 Colum. J. L. \& ARTs 668 (2011).

9. Id. at 665 .

10. D. Gervais, Application of an Extended Collective Licensing Regime in Canada: Principles and Issues Related to Implementation (hereinafter Canada Report), at 7, available at https:// www.academia.edu/7101677/Extended_Collective_Licensing_Regime_in_Canada (last visited on Jan. 27, 2017).

11. Fragmented copyright refers to copyright that is sliced and diced by type of media, distributor, country, date, language, etc. See D. Gervais \& A. Maurushat, Fragmented Copyright, Fragmented Management: Proposals to Defrag Copyright Management, 2 CAN. J. L. \& Tесн. 15-6 \& 23 (2003).

12. Canada Report, at 7.

13. Id.

14. Id. at 15.

15. Id. at 16 .

16. See A brief description of the Chinese Copyright Act (Revised Draft) 关于《中华人民共 和国著作权法》(修改草案) 的简要说明, art.13, available at http://www.law-lib.com/fzdt/ newshtml/fzjd/20120331202211.htm (last visited on Jan. 31, 2017). It read:

$\mathrm{CMC}$ is an important symbol to measure the level of copyright protection in a country or region. It is also the important means to use the work legitimately. Recently, a series of CMOs have been created in China. However, the cognition and knowledge of all sectors of society about CMOs still needs being improved. There are still many authors who have not joined in CMOs. In reality, it is often the case that the user is willing to use the work legally but cannot find the rightholder. To address the dilemma of use of works, basing on Chinese distinct national conditions, the ECLs have been created generally following the ECLs legislation in the Nordic countries. The CMOs with broad representativeness can operate an ECL scheme on behalf of non-members under the authorization of NCAC.

17. The third amendment to the Chinese Copyright Act, ch. V (Copyright Utilization) 
18. Dr. Mihály Ficsor argues that it might not be realistic (at least for now) to think that that any binding international regulation on the ECL will be implemented.

19. It is difficult to research the effects of some systems. This paper deduces the operating results of the system theoretically rather than conducting an empirical study.

20. D. Gervais argue that it is not excessively burdensome for rightsholders to exclude themselves from an ECL. See Canada Report, at 18.

21. D. Sinacore-Guinn, Collective Administration of Copyrights and Neighbouring Rights: International Practices, Procedures, and Organizations 405 (1993).

22. Canada Report, at 29.

23. Supra note 3, at 483.

24. M. Ficsor, Collective Management of Copyright and Related Rights at A Triple Crossroads: Should It Remain Voluntary or May It Be "Extended" or Made Mandatory?, Copyright Bull. 9 (Oct. 2003), available at http://portal.unesco.org/culture/en/ files/14935/10657988721Ficsor_Eng.pdf/Ficsor\%2BEng.pdf (last visited on Jan. 23, 2017).

25. WIPO study (1990), $₫ 264$.

26. See the presentation by the Motion Picture Association in the Public Hearing on the Governance of Collective Rights Management at Brussels in the E.U., Apr. 23, 2010 (hereinafter Public Hearings in the E.U.), at 1, available at http://ec.europa.eu/internal_ market/copyright/docs/management/hearing20100423/panel_1_mpa_en.pdf (last visited on Jan. 27, 2017).

27. L. Wasoff, If Mass Digitization Is the Problem, Is Legislation the Solution? Some Practical Considerations Related to Copyright, 34 Colum. J. L. \& ARTs 746 (2010-2011).

28. Canada Report, at 5.

29. Id. at 26.

30. Canada Report, at 40. The approach has been included in the UK copyright law's ECL. See supra note 18, art. 16(6); The Copyright and Rights in Performances (Extended Collective Licensing) Regulations 2014, art. 16(6), available at http://www.legislation.gov.uk/ ukdsi/2014/9780111116890 (last visited on Jan. 30, 2017).

31. Supra note 27, at 735 .

32. Id.

33. Id.

34. M. Einhorn, Media, Technology and Copyright 88 (2005).

35. L. Lessig, The Future of Ideas: The Fate of The Commons in a Connected World 201 (2001).

36. See the presentation by Motion Picture Association, in Public Hearings in the E.U., at 1, available at http://ec.europa.eu/internal_market/copyright/docs/management/ hearing20100423/panel_1_mpa_en.pdf (last visited on Jan. 27, 2017).

37. See the presentation of Jeremy Rollison, Director, European Digital Media Association Secretariat, in Public Hearings in the E.U., at 2, available at http://ec.europa.eu/internal_ 
market/copyright/docs/management/hearing20100423/panel_3_edima_en.pdf (last visited on Jan. 27, 2017).

38. J. Ginsburg, "The Exclusive Right to Their Writings": Copyright and Control in the Digital Age, 54 Me. L. Rev.199 (2002).

39. The fees charged under this regime would be higher than in the control regime. See A. Peukert, A Bipolar Copyright System for the Digital Network Environment, 28 Hastings Comm. \& EnT. L. J. 25 (2005-2006).

40. C. Hauptmann, Relationship between Collective Rights Managers and Commercial Users, in Public Hearings in the E.U., at 8, available at http://ec.europa.eu/internal_market/copyright/ docs/management/hearing20100423/panel_3_rtl group_en.pdf (last visited on Jan. 27, 2017).

41. Koji Okumura, Collective Management of Copyright and Neighbouring Rights in Japan, in Collective Management of Copyright and Neighboring Rights 404 (D. Gervais ed., 2010).

42. Supra note 40.

43. G. Lunney, The Death of Copyright: Digital Technology, Private Copying, and the Digital Millennium Copyright Act, 87 VA. L. Rev. 826 (2001).

44. Supra note 37.

45. The new business models of distributing copyright works might be cut off by a compulsory CMC or similar system. See S. Masur \& C. Katz, ISP Licensing-A Carrot to the Stick of Three-Strikes Laws, 13 SMU Sci. \& Tech. L. Rev.294 (2009-10).

46. Rightsholders' retention of control over their works is conducive to the innovation of business models that facilitate the communication of those works. See J. Ginsburg, Legal Protection of Technological Measures Protecting Works of Authorship: International Obligations and the US Experience, 29 CoLuM. J. L. \& ARTs 12 (2005-2006).

47. Haijun Lu, Chinese Collective Management of Copyright: The Need for Extensive Changes, 6 QueEn Mary J. Intell. Prop. 205 (2016).

48. H. Ranaivoson et al., The Costs of Licensing for Online Music Services: An Exploratory Analysis for European Services, 21 Mich. ST. U. Coll. L. Int'L L. Rev. 671 (2013).

49. Peukert, supra note 39.

50. N. Netanel, Impose A Noncommercial Use Levy To Allow Free Peer-To-Peer File Sharing, 17 Harv. J. L. \& Tесн. 35-58 (2003-4).

51. Peukert, supra note 39.

52. Supra note 50, at 43.

53. Id. at 44 .

54. Id. at 65-66.

55. Id. at 67.

56. S. Dusollier \& C. Colin, Peer-to-Peer File Sharing and Copyright: What Could Be the Role of Collective Management?, 34 Colum. J. L. \& ARTS 835 (2010-11).

57. Jiang Ye, Changing Tides of Collective Licensing in China, 21 Mich. St. Int'L. L. Rev. 735- 
6 (2013).

58. R. Walkert, Negotiating The Unknown: A Compulsory Licensing Solution to the Orphan Works Problem, 35 CARDOZo L. Rev.1012 (2013-14).

59. T. Koskinen-Olsson, Collective Management in the Nordic Countries, in supra note 41, at 304.

60. To prevent abuse of the privilege of the legally authorized use of orphan works, which would prevent the creation of new orphan works and result in possibly duplicated labour to search for the rightsholders, it is necessary to require that users register necessary information about their orphan works with the competent authority.

61. US Copyright Office, Report on Orphan Works, Jan. 2006 (hereinafter US Report on Orphan Works), at 127, available at http://www.copyright.gov/orphan/orphan-report-full. pdf (last visited on Jan. 27, 2017).

62. The US Report on Orphan Works, at 72.

63. Id.

64. Id. at 73 .

65. Id. at 78 .

66. Id. at 127 .

67. Id.

68. In the "Recommended Statutory Language" (Section 514: Limitations on Remedies: Orphan Works) of the US Report on Orphan Works, the user concerned is defined as "the infringer"; the use concerned is defined as "the infringement." See id. at 127. [Emphasis added]

69. Berne Convention arts. $10 \& 11$ [bis].

70. E.g., most, if not all, of ECLs concern particular uses. See supra note 8, at 667.

71. The US Report on Orphan Works, at 94.

72. The reservation of 'exclusivity' to rightsholders, including the right to halt use, is the key element in deciding whether an approach to orphan works is supportable, especially by rightsholders. See supra note 27, at 738.

73. T. Bell, Fair Use v. Fared Use: The Impact of Automated Rights Management on Copyright's Fair Use Doctrine, 76 N.C.L. REv. 557 (1998). [Emphasis added]

74. Supra note 3, at 491-92.

75. Supra note 8, at 669.

76. Berne Convention art. 9(2).

77. S. Ricketson, The Berne Convention for the Protection of Literary And Artistic Works: 1886-1986, 482 (1987).

78. Berne Convention arts. $2[$ bis $](2), 10 \& 10[$ bis $]$.

79. Id. arts. $11[$ bis $](2) \& 13$.

80. Supra note 3, at 487-90.

81. Supra note 57, at 740-1.

82. Canada Report, at 15. 
83. Supra note 3, at 475 (n. 10).

84. MCSC Annual Report (2012), at 14-5, available at http://www.mcsc.com.cn/pdf/phpNlBlno. pdf (last visited on Jan. 27, 2017).

85. It is has been confirmed personally by Chinese lawmakers that the ECL in the drafts of the third amendment only covers rightsholders in Mainland China.

86. Unfortunately, this information was also obtained through personal conversations.

87. Jichao Ma (Deputy Director-General of CAVCA), On the ECL in the Chinese jurisdiction 我 国建立延伸集体管理制度探讨, unpublished paper (Dec. 16 2013).

88. Id.

89. Id.

90. The second draft of the Chinese Copyright Act, art. 70(1). In the case of users who invoke the copyrights that are difficult to enforce and police individually - and who have paid CMOs pursuant to agreements - when non-members sue those users for copyright infringement based on the same copyrights, the users should stop using and compensating the rightsholders 'according to' the royalties charged by the CMOs in the same circumstances. Unless the users are operating in bad faith, the users have actual knowledge that the rightsholders do not permit the use, according to Article 70(2). Article 70(1) of the second draft is a revised version of Article 70 of the first draft, in which users are exempt from liability to pay damages. Instead, they should pay the rightsholders 'according to' the royalties charged by the CMOs in the same circumstance. The original version in the first draft, almost without any prerequisites of the limitation on the remedies, blatantly deprives the rightsholders of their exclusive copyrights, which need not be detailed further. The version in the second draft limits the restrictions to some degree. The most recent draft inherits the above clause, which is rearranged and placed in Section 74(1). Compared to the original version in the first draft, the Chinese government's ambition comes in a variety of guises. Thus, details are provided for the purpose of raising readers' awareness of this issue.

91. By the end of 2013, the membership size of MCSC (the first Chinese CMO, founded in 1992) was just 7,301. See MCSC Annual Report (2013), available at http://www.mcsc.com. $\mathrm{cn} / \mathrm{pdf} / \mathrm{php2015abc.pdf}$ (last visited on Jan. 27, 2016).

92. Principles (13) in the Conclusion chapter of the 2002 WIPO publication on CMC provides: “... such joint management organizations [with the privilege of an ECL] should give appropriate guarantees to their licensees against individual claims of rights owners who are not represented by the organization but whose works are also covered by a blanket license." See M. Ficsor, Collective Management of Copyright and Related Rights, WIPO Publication No. 855 (E), 2002, at 161, available at ftp://ftp.wipo.int/pub/library/ebooks/ wipopublications/wipo_pub_855e.pdf (last visited on Jan. 27, 2016). In an ECL, one can argue that the above principle should be highlighted to guarantee that users' interests will be protected reliably. However, in an ECL, non-members generally have a right to both individual remuneration and opt out. Section 70(1) in the second draft does not clearly state 
whether non-members include opt-outers. If non-members include opt-outers, then opting out makes no sense. Even if the provision only covers non-opt-outers, the limitations on the remedies in that provision imposes the opt-out burden on the rightsholders in that if they want more compensation, they must opt out.

93. The ECLs might challenge the exclusivity of copyrights and the non-formalities threshold for copyright protection under the Berne Convention. See supra note 3, at 481-3.

94. Berne Convention art. 11[bis](2).

95. Supra note 8 , at 667.

96. Supra note 3, at 498.

97. Information obtained from Dr. Mihály Ficsor.

98. See generally supra note 57.

99. The problems and improvement of China's collective management of copyright have been elaborated in another related article of the author. See Lu, supra note 47, at 175-206 (2016).

100. In some EU instruments, ECLs are included as legitimate arrangements for addressing copyright issues in special cases. See Article 3(2) of the Satellite and Cable Directive (Council Directive 93/83/EEC of 27 September 1993); Recital (18) of the Information Society (Copyright) Directive (Directive 2001/29/EC); Recital (24) of the Orphan Works Directive (2012/28/EU of 25 October 2012). Other than the ECLs in the Nordic countries, there are attempts or practices related to ECL or similar arrangements in other jurisdictions such as Hungary, the UK, Slovak and Germany. Although ECLs originate from a small and homogeneous society, the ECL's development in the EU may support the arguments that the ECLs can be successful in a bigger and more heterogeneous society. In reality, in contrast with the EU, the conditions of China are more complex. It is fair to say that the EU countries enjoy a higher level of homogenization than the society of China thanks to the continuing European integration efforts. Even if ECLs can be successful in a heterogeneous society, because there are many other preconditions for the ECLs to be successful, China needs to take prudent attitude in the transplantation of ECLs.

101. Supra note 3, at 495.

102. Id.

103. Supra note 8, at 665.

104. Supra note 3, at 495.

105. Id. at 496.

106. Id.

107. Kaizhong Hu, On Construction of Chinese System of Extended Collective Licence 构建我国 著作权延伸性集体管理制度的思考, 158 J. L. \& Bus. 法商研究 25 (2013). 